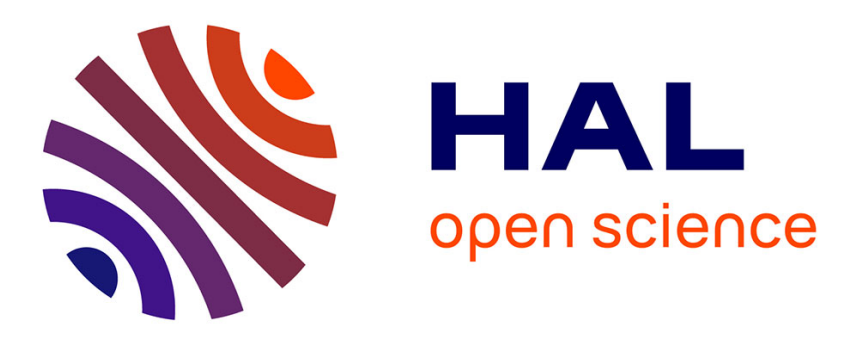

\title{
Terahertz HgTe Nanocrystals: Beyond Confinement
}

Nicolas Goubet, Amardeep Jagtap, Clément Livache, Bertille Martinez, Hervé Portalès, Xiang Zhen Xu, Ricardo Lobo, Benoit Dubertret, Emmanuel Lhuillier

\section{- To cite this version:}

Nicolas Goubet, Amardeep Jagtap, Clément Livache, Bertille Martinez, Hervé Portalès, et al.. Terahertz HgTe Nanocrystals: Beyond Confinement. Journal of the American Chemical Society, 2018, 140 (15), pp.5033-5036. 10.1021/jacs.8b02039 . hal-01764916

\section{HAL Id: hal-01764916 https://hal.science/hal-01764916}

Submitted on 4 Jul 2018

HAL is a multi-disciplinary open access archive for the deposit and dissemination of scientific research documents, whether they are published or not. The documents may come from teaching and research institutions in France or abroad, or from public or private research centers.
L'archive ouverte pluridisciplinaire HAL, est destinée au dépôt et à la diffusion de documents scientifiques de niveau recherche, publiés ou non, émanant des établissements d'enseignement et de recherche français ou étrangers, des laboratoires publics ou privés. 


\title{
TeraHertz HgTe nanocrystals: beyond confinement
}

\author{
Nicolas Goubet ${ }^{1,2,3}$, Amardeep Jagtap ${ }^{1}$, Clément Livache ${ }^{1,2,3}$, Bertille Martinez ${ }^{1,2,3}$, Hervé Portalès ${ }^{4}$, \\ Xiang Zhen $\mathrm{Xu}^{2,3}$, Ricardo P.S.M. Lobo ${ }^{2,3}$, Benoit Dubertret ${ }^{2,3}$, Emmanuel Lhuillier $^{1^{*}}$ \\ ${ }^{1}$ Sorbonne Université, CNRS, Institut des NanoSciences de Paris, INSP, F-75005 Paris, France \\ ${ }^{2}$ LPEM, ESPCI Paris, PSL University, CNRS, F-75005 Paris, France \\ 3 Sorbonne Université, CNRS, LPEM, F-75005 Paris, France \\ ${ }^{4}$ Sorbonne Universités, UPMC Univ Paris 06, CNRS, UMR 8233, MONARIS, 4 Place Jussieu, 75005 Paris, France
}

\section{Supporting Information Placeholder}

\begin{abstract}
We report the synthesis of nanocrystals with optical feature in the $\mathrm{THz}$ range. To do so, we develop a new synthetic procedure for the growth of $\mathrm{HgTe}, \mathrm{HgSe}$ and $\mathrm{HgS}$ nanocrystals, with strong size tunability from $5 \mathrm{~nm}$ to $200 \mathrm{~nm}$. This is used to tune the absorption of the nanocrystal all over the infrared range up to the teraHertz (from $2 \mu \mathrm{m}$ to $65 \mu \mathrm{m}$ for absorption peak and even $200 \mu \mathrm{m}$ for cut-off wavelength). The interest for this procedure is not limited to large size since for small objects we demonstrate low aggregation, good shape control (i.e. spherical object) while using non-expansive and simple mercury halogenide precursors. By integrating these nanocrystals into an electrolyte-gated transistor, we evidence a change of carrier density from p-doped to $n$-doped as the confinement is vanishing.
\end{abstract}

Colloidal quantum dots (CQD) have garnered significant scientific and technological interests because of their tunable optical features from ultraviolet (UV) to infrared (IR). While their photoluminescence appears as the first mass market application, CQD are actually as interesting for the design of low cost optoelectronic devices that combine the ease of processing of solution-processable material with the robustness of inorganic systems. This is especially true in the IR range where current technologies remain pricy. CQD offer an interesting platform, however reaching mid $(\lambda>3 \mu \mathrm{m})$ and far infrared wavelength is challenging on a material perspective. ${ }^{1-3}$

Only few materials can address absorption tunability up to the terahertz range: graphene $e^{4}$, doped semiconductors $(\mathrm{Si}, \mathrm{InSb})^{5,6}$ and topological insulators such as $\mathrm{Bi}_{2} \mathrm{Se}_{3}{ }^{7}$. However, the strong field localization of terahertz plasmon in a subwavelength volume makes that materials need to be designed in gratings. The wet chemical synthesis can be a potential alternative and easy way to produce terahertz materials. To reach this goal, the current synthetic procedures need to be pushed toward CQD-based terahertz technology. Mercury chalcogenides $\left(\mathrm{HgX}: \mathrm{HgS}^{8,9} \mathrm{HgSe}^{10-12}\right.$ and $\mathrm{HgTe}^{13}$ ) have reached the highest maturity to address this part of the electromagnetic spectrum because they combine mid-IR tunable optical features with photoconduction. Lots of effort have been made for the integration of $\mathrm{HgX} \mathrm{CQD,} \mathrm{including} \mathrm{the} \mathrm{design} \mathrm{of} \mathrm{pho-}$ toconductive ${ }^{14,15}$, photovoltaic, ${ }^{16}$ phototransistor, devices ${ }^{17}$, plasmon assisted photodetection, ${ }^{18-20}$ multicolor detection ${ }^{21,22}$ and even hybrid with graphene ${ }^{23,24}$. A recent review on the field is given in ref ${ }^{25}$.
Among $\mathrm{HgX}, \mathrm{HgTe}$ is the compound that leads to the best performances, with the lowest dark current and the fastest time response. ${ }^{25}$ However, the current state of the art synthesis for mid-IR HgTe CQD relies on Keuleyan et al. synthesis and keep suffering from several limitations, which are discussed in more details in the supporting information. ${ }^{26,27}$ In particular the material grows with an anisotropic shape (tetrapod or tetrahedron, see figure S1-S4) which tends to self-assemble into pairs (see figure S4) and leads to a loss of colloidal stability even for moderate size CQD. This is extremely detrimental to the design of pinhole free layer for vertical geometry device. Moreover, the final objects are strongly faceted and present the least reactive facet, which is limiting for growth of heterostructures. This perspective is even more challenging due to the high reactivity of mercury with chalcogenides. Consequently, nucleation and growth steps are difficult to be time-separated and low temperature growth is used in current synthesis $\left(60-120^{\circ} \mathrm{C}\right)$, making the obtained material incompatible with usual high temperature $\left(200-300^{\circ} \mathrm{C}\right)$ growth process of wide band gap colloidal material. ${ }^{8,28}$ In term of shape control HgTe has not yet reached the maturity of CdSe. 2D HgTe platelets have recently been proposed by Izquierdo et al..$^{29}$ but they remain limited to the near-IR range. Shen et $\mathrm{al}^{30}$ have also proposed the use of a more reactive precursor such as bis-(trimethylsilyl)telluride (TMSTe) as a way to improve sphericity and aggregation. However, TMSTe is expensive and has a very limited stability, which prevents such synthesis to be viable at least at the industrial scale. Last, the current range of size spans from 3 to $20 \mathrm{~nm}$, which makes that the obtained material is still strongly confined since $\mathrm{HgTe}$ presents a large exciton Bohr radius of $40 \mathrm{~nm} .{ }^{31}$ This prevents current material to address wavelengths above $12 \mu \mathrm{m}^{27,32}$ and also limits the emergence of topologically protected states which are expected for poorly confined objects. ${ }^{33,34}$ In this paper, we report a new and simple synthetic procedure for the growth of HgTe CQD. We demonstrate size control from $5 \mathrm{~nm}$ to above $200 \mathrm{~nm}$, which allows for the first time to cover the whole infrared range from $2 \mu \mathrm{m}$ up to the $\mathrm{THz}$ range $(65 \mu \mathrm{m})$ with a single material. In particular, we focus on long wavelengths $(10-100 \mu \mathrm{m}$ range), which are non-addressable based on previously reported synthesis. We also integrate these materials into electrolyte-gated transistors and demonstrate that HgTe CQD switch from p-type for the smallest size to n-type for the largest CQD.

To achieve a higher degree of control on HgTe CQD synthesis, we investigate for less reactive precursors. Our approach is based on the simultaneous injection of $\mathrm{HgX}_{2}$ (with $\mathrm{X}=\mathrm{Cl}, \mathrm{Br}$ or I) and $\mathrm{Te}$ complexed with trioctylphosphine (TOP) in a hot solution of 
oleylamine. It is worth noting that the procedure can be extended to the growth of $\mathrm{HgSe}$ and $\mathrm{HgS}$ (see figure $\mathrm{S} 9$ and $\mathrm{S} 10$ ), while using $\mathrm{NaBH}_{4}$ reduced Se and elemental sulfur in oleylamine, respectively.
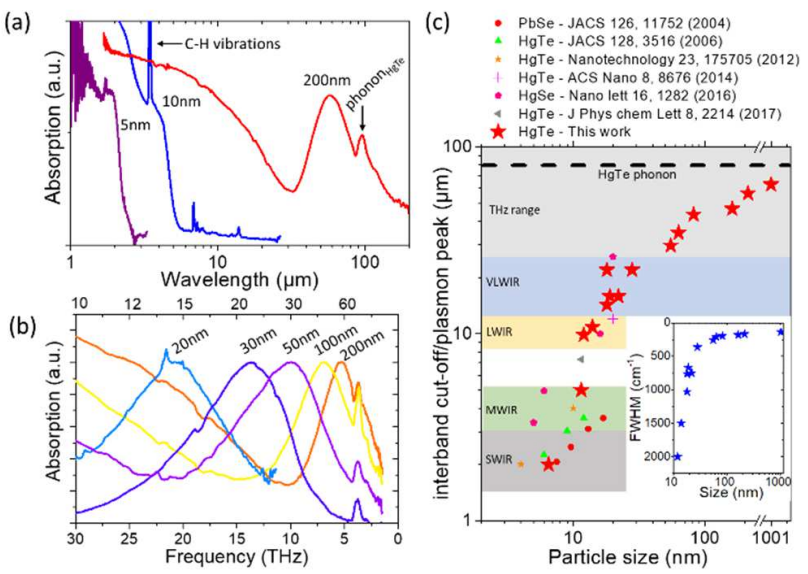

Figure 1. (a). absorption spectra of $\mathrm{HgTe} C \mathrm{CQD}$ with various sizes. (b) absorption spectra of HgTe CQD with various sizes, presenting a plasmonic feature in the LWIR, VLWIR or THz range. (c) Cut off wavelength of the interband transition (for material without plasmonic feature) and plasmonic peak wavelength (for doped material) as a function of the CQD size (diameter for spherical object). SWIR corresponds to Short-Wavelength Infrared range (1.5 to 3 $\mu \mathrm{m}$ ), MWIR to Mid-Wavelength Infrared range (3 to $8 \mu \mathrm{m}$ ), LWIR to Long-Wavelength Infrared range (8 to $12 \mu \mathrm{m}$ ), and VLWIR to Very Long-Wavelength Infrared range (12 to $30 \mu \mathrm{m})$. Inset: full width at half maximum (FWHM) of intraband peak as function CQD size.

The size of the CQD is driven by three key parameters, which are temperature, the reaction time and the chosen mercury halide precursor. By tuning the reaction temperature from $120^{\circ} \mathrm{C}$ up to 340 ${ }^{\circ} \mathrm{C}$, the mean size of the CQD can be tuned from $5 \mathrm{~nm}$ up to 200 $\mathrm{nm}$, see Figure 1c, 2 and Figure S5. Thus, it is possible to obtain absorption all over the infrared range from $2 \mu \mathrm{m}$ up to $65 \mu \mathrm{m}$, see Figure 1. This approach presents the key advantages to both be able to synthesize small CQD sizes with sharp excitonic transition, but is also well suited to obtain large CQD, which are able to address long wavelength $(>12 \mu \mathrm{m})$. Figure $1 \mathrm{~b}$ shows how the LongWavelength Infrared range (LWIR, 8-12 $\mu \mathrm{m}$ range), Very LongWavelength Infrared range (VLWIR, 12-20 $\mu \mathrm{m}$ range) and THz $(\lambda>30 \mu \mathrm{m})$ can be finely addressed using the developed protocol. The optical features have been pushed to an energy typically twice smaller than the previous record. ${ }^{10}$

In the case of large CQD, the spectrum is made of two components: an interband absorption at high energy and an intraband/plasmonic peak at low energy, see Figure 1a and b. The exact nature of the long wavelength feature actually depends on particle size and doping level. ${ }^{8}$ The energy of this transition can be made low enough, so that the peak overlaps with the absorption resulting from the LO phonon line (at $123 \mathrm{~cm}^{-1}$ ). The Raman spectrum in figure $\mathrm{S} 11 \mathrm{con}-$ firms the phonon character of this line. Another striking behavior is the exceptional narrowness of the intraband/plasmonic peak (< $200 \mathrm{~cm}^{-1}$ ) compared to what it can be for doped nanocrystals of $\mathrm{Si}^{35}$ or oxides ${ }^{36-38}$ (with a FWHM $>1000 \mathrm{~cm}^{-1}$ ).

While the role of reaction time is rather trivial with an increase of the final size with time, the role of halide is more complex. We observe that chloride leads to larger objects compare to the other halides ( $>\mathrm{Br}>\mathrm{I})$, see Figure 2. This trend is confirmed by following the absorption of the solution at $415 \mathrm{~nm}$, which is the signature of the amount of crystalline $\mathrm{HgTe}$, see figure S5 ${ }^{32}$ Even at low temperature $\left(120^{\circ} \mathrm{C}\right)$, the reaction is almost complete after $3 \mathrm{~min}$ in the case of $\mathrm{HgCl}_{2}$, while it is still unfinished after $3 \mathrm{~h}$ while using $\mathrm{HgI}_{2}$. As shown in Figure 2a, d and e, iodine precursor leads to more faceted objects. This may be attributed to the soft base character of iodine that allow a better bonding and poisoning surface made of soft acid mercury. ${ }^{39}$

As recently proposed by Shen et al, ${ }^{30}$ it is possible to tune the magnitude of the long wavelength peak of the absorption spectra while tuning the reaction stoichiometry. For moderate size CQD (12-40 $\mathrm{nm}$ ), only the interband contribution is observed in the case of stoichiometric reaction $(\mathrm{Hg}: \mathrm{Te}=1: 1)$, while the long wavelength feature is obtained in $\mathrm{Hg}$ rich condition, see figure $\mathrm{S} 8$. $\mathrm{Hg}$ rich material tends to be n-type doped, which favor the observation of the intraband/plasmonic feature as observed for $\mathrm{HgS}$ and $\mathrm{HgSe}$ which are intrinsically n-doped. ${ }^{40}$

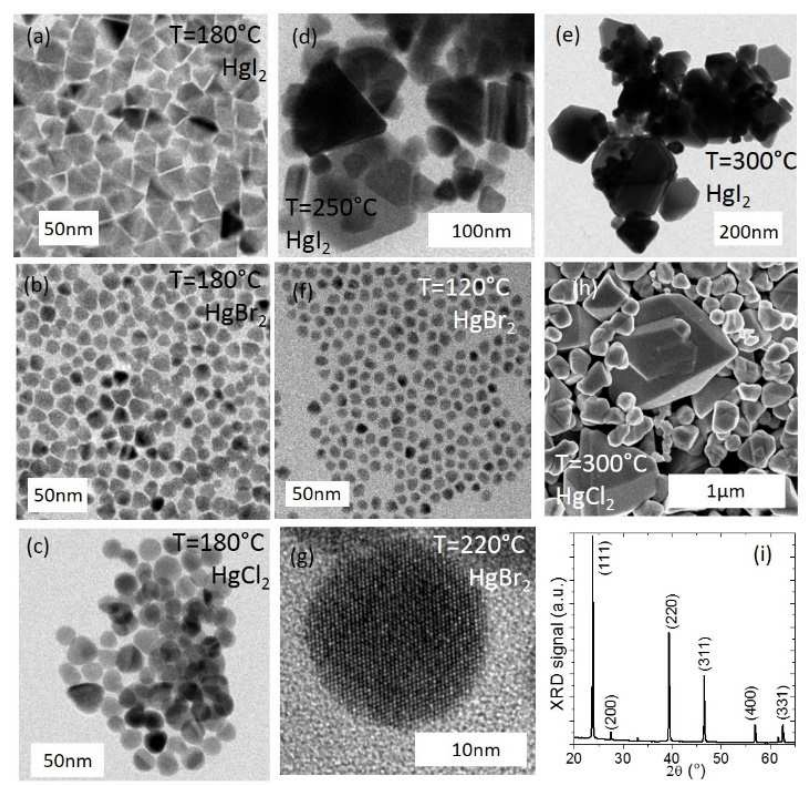

Figure 2 (a), (b) and (c) are Transmission Electron Microscopy (TEM) images of $\mathrm{HgTe} C Q D$ synthetized at $180^{\circ} \mathrm{C}$ with $\mathrm{HgI}_{2}$, $\mathrm{HgBr}_{2}$ and $\mathrm{HgCl}_{2}$ as $\mathrm{Hg}$ precursor, respectively. (d) and (e) are TEM images of $\mathrm{HgTe}^{\mathrm{CQD}}$ synthetized using $\mathrm{HgI}_{2}$ as precursor at $250^{\circ} \mathrm{C}$ and $300^{\circ} \mathrm{C}$, respectively. (f) and (g) are low and high resolution images of spherical HgTe CQD with limited aggregation. (h) is an Scanning Electron Microscopy (SEM) image of HgTe CQD synthetized at $300^{\circ} \mathrm{C}$ using $\mathrm{HgCl}_{2}$ and (i) the corresponding X-ray diffractogram.

Transmission electron microscopy (TEM) images (Figure 2) clearly show a limited aggregation. Moreover, it is possible at low temperature to obtain almost nearly spherical objects, see Figure 2 $\mathrm{f}$ and $\mathrm{g}$. As shown in Figure $\mathbf{2} \mathrm{d}$, e and h, the size dispersion is large for large objects. However, this is not critical since the plasmon linewidth of CQD is driven by the doping level rather than the confinement. ${ }^{8}$ The crystalline nature of the obtained material is well revealed by high resolution TEM (Figure $\mathbf{2} \mathrm{g}$ ) as well as by X-ray diffraction (Figure 2i). The diffraction pattern is consistent with the zinc-blende structure of HgTe.

To better highlight the role of doping on the optical properties, we integrate the film of HgTe CQD into electrolyte-gated transistor (see Figure 3a for a scheme of the device) ${ }^{41}$ Such gating method is convenient because it combines low bias operation thanks to the large gate capacitance with air operability. As the nanoparticle size is increased, the material switches from p-type (conduction under hole injection) (Figure 3b) to ambipolar (Figure 3c) and finally to 
n-type only (conduction under electron injection) for the largest sizes (Figure 3d). This change of behavior is further quantized by the increase of the ratio of electron mobility over hole mobility while the band gap is reduced, see Figure $3 \mathrm{e}$.

This emergence of n-type conduction is similar to what has been observed for $\mathrm{HgS}^{8}$ and $\mathrm{HgSe}^{10}$ nanocrystals. Due to the combination of narrow band gap and high work function in $\mathrm{HgX} C Q D$, the material can be reduced by the environment. ${ }^{42}$ This reduction however occurs for much larger size (ie lower confinement) because of the lower work function of $\mathrm{HgTe}$ material compared with $\mathrm{HgS}$ and $\mathrm{HgSe}^{40}$ This is interesting on an applied point of view because it preserves the gate effect even for large particles, while for other chalcogenides gate control is lost due to their too metallic character. ${ }^{43}$ This means that even for the largest particle the number of carrier per particle remains in the range of what can be tuned by electrolyte gating (0-6 electrons typically). As a result, the long wavelength feature observed in the absorption spectra is probably not fully plasmonic and preserves an intraband character.
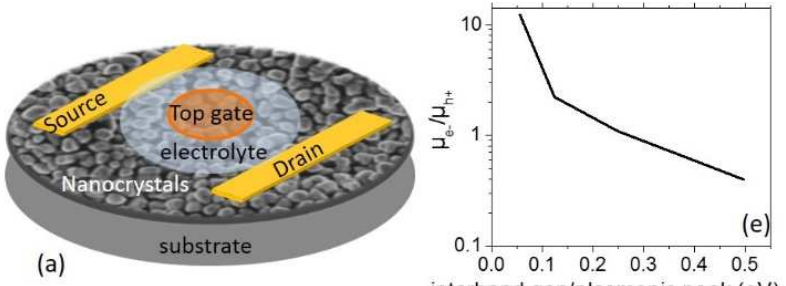

interband gap/plasmonic peak (eV)
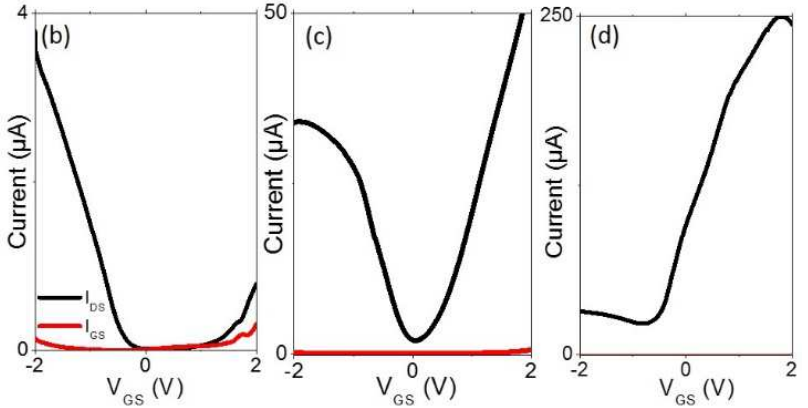

Figure 3 (a) Scheme of an electrolyte gated transistor which channel is made of $\mathrm{S}^{2-}$ capped HgTe CQD. Transfer curves (current as a function of gate bias) for HgTe CQD with an excitonic feature at $4000 \mathrm{~cm}^{-1}$ (b), a cut off at $2000 \mathrm{~cm}^{-1}$ (c) and a plasmonic feature at $450 \mathrm{~cm}^{-1}$ (d). (e) Variation of the ratio of the electron mobility over the hole mobility as a function of the interband gap.

In summary, we report a new synthetic procedure for $\mathrm{HgTe}$ nanocrystal, which allows an unprecedented tuning of nanocrystal sizes from small scale to far beyond the exciton Bohr radius. This leads to the first demonstration of colloidal nanocrystals with optical feature in the $\mathrm{THz}$ range. The synthesis is also promising for small size because of the low aggregation and good shape control (ie spherical objects) of the synthetized nanocrystals. Moreover, the synthesis relies on low reactivity precursor of mercury with low cost. The transport properties of the nanocrystals show a change of majority carrier density from p-type for small CQD to n-type for the largest object.

\section{ASSOCIATED CONTENT}

\section{Supporting Information}

The Supporting Information is available free of charge on the ACS Publications website.
Additional information includes experimental details on $\mathrm{HgTe}$, $\mathrm{HgSe}$ and $\mathrm{HgS}$ nanocrystal synthesis, TEM pictures of HgTe CQD shape evolution with time and self-assembly in dimer, reactivity of different $\mathrm{HgX}$ precursors, absorption spectra with different stoichiometry of HgTe CQD, size distribution, experimental details on electron microscopies, UV-Vis, FTIR and Raman spectroscopies (PDF)

\section{AUTHOR INFORMATION}

\section{Corresponding Author}

*el@insp.upmc.fr

Notes

The authors declare no competing financial interests.

\section{ACKNOWLEDGMENT}

EL acknowledges the financial support of the European Research Council (ERC) starting grant (blackQD $-\mathrm{n}^{\circ} 756225$ ). We acknowledge the use of clean-room facilities from the "Centrale de Proximité Paris-Centre". We thank Agence Nationale de la Recherche for funding through grant Nanodose and H2DH. This work has been supported by the Region Ile-de-France in the framework of DIM Nano-K. This work was supported by French state funds managed by the ANR within the Investissements d'Avenir programme under reference ANR-11-IDEX-0004-02, and more specifically within the framework of the Cluster of Excellence MATISSE. This work is also supported by the NextIR grant funded by Nexdot.

\section{REFERENCES}

(1) McDonald, S. A.; Konstantatos, G.; Zhang, S.; Cyr, P. W.; Klem, E. J. D.; Levina, L.; Sargent, E. H. Nat Mater 2005, $4(2), 138$.

(2) Pietryga, J. M.; Schaller, R. D.; Werder, D.; Stewart, M. H.; Klimov, V. I.; Hollingsworth, J. A. J. Am. Chem. Soc. 2004, 126 (38), 11752. Kershaw, S. V.; Susha, A. S.; Rogach, A. L. Chem. Soc. Rev. 2013, 42 (7), 3033.

(4) Low, T.; Avouris, P. ACS Nano 2014, 8 (2), 1086.

(5) Withayachumnankul, W.; Shah, C. M.; Fumeaux, C.; Kaltenecker, K.; Walther, M.; Fischer, B. M.; Abbott, D.; Bhaskaran, M.; Sriram, S. Advanced Optical Materials 2013, 1 (6), 443.

(6) Isaac, T. H.; Barnes, W. L.; Hendry, E. Appl. Phys. Lett. 2008, 93 (24), 241115.

(7) Pietro, P. D.; Ortolani, M.; Limaj, O.; Gaspare, A. D.; Giliberti, V.; Giorgianni, F.; Brahlek, M.; Bansal, N.; Koirala, N.; Oh, S.; Calvani, P.; Lupi, S. Nat Nano 2013, 8 (8), 556.

(8) Shen, G.; Guyot-Sionnest, P. J. Phys. Chem. C 2016, 120 (21), 11744.

(9) Yoon, B.; Jeong, J.; Jeong, K. S. J. Phys. Chem. C 2016, 120 (38), 22062.

(10) Lhuillier, E.; Scarafagio, M.; Hease, P.; Nadal, B.; Aubin, H.; Xu, X. Z.; Lequeux, N.; Patriarche, G.; Ithurria, S.; Dubertret, B. Nano Lett. 2016, 16 (2), 1282.

(11) Deng, Z.; Jeong, K. S.; Guyot-Sionnest, P. ACS Nano 2014, 8 (11), 11707.

(12) Jeong, J.; Yoon, B.; Kwon, Y.-W.; Choi, D.; Jeong, K. S. Nano Lett. 2017, 17 (2), 1187.

(13) Kovalenko, M. V.; Kaufmann, E.; Pachinger, D.; Roither, J.; Huber, M.; Stangl, J.; Hesser, G.; Schäffler, F.; Heiss, W. J. Am. Chem. Soc. 2006, 128 (11), 3516.

(14) Keuleyan, S.; Lhuillier, E.; Brajuskovic, V.; Guyot-Sionnest, P. Nat Photon 2011, 5 (8), 489. 
(15) Lhuillier, E.; Keuleyan, S.; Rekemeyer, P.; Guyot-Sionnest, P. Journal of Applied Physics 2011, 110 (3), 033110.

(16) Guyot-Sionnest, P.; Roberts, J. A. Appl. Phys. Lett. 2015, 107 (25), 253104.

(17) Chen, M.; Lu, H.; Abdelazim, N. M.; Zhu, Y.; Wang, Z.; Ren, W.; Kershaw, S. V.; Rogach, A. L.; Zhao, N. ACS Nano 2017, 11 (6), 5614.

(18) Yifat, Y.; Ackerman, M.; Guyot-Sionnest, P. Appl. Phys. Lett. 2017, 110 (4), 041106.

(19) Tang, X.; Wu, G. fu; Lai, K. W. C. J. Mater. Chem. C 2017, 5 (2), 362.

(20) Chen, M.; Shao, L.; Kershaw, S. V.; Yu, H.; Wang, J.; Rogach, A. L.; Zhao, N. ACS Nano 2014, 8 (8), 8208.

(21) Lhuillier, E.; Robin, A.; Ithurria, S.; Aubin, H.; Dubertret, B. Nano Lett. 2014, 14 (5), 2715.

(22) Tang, X.; Tang, X.; Lai, K. W. C. ACS Photonics 2016, 3 (12), 2396.

(23) Tang, X.; Wu, G. F.; Lai, K. W. C. Appl. Phys. Lett. 2017, 110 (24), 241104

(24) Nengjie, H.; Shuchi, G.; Gerasimos, K. Advanced Materials 2017, 29 (17), 1606576.

(25) Lhuillier, E.; Guyot-Sionnest, P. IEEE Journal of Selected Topics in Quantum Electronics 2017, 23 (5), 1.

(26) Keuleyan, S.; Lhuillier, E.; Guyot-Sionnest, P. J. Am. Chem. Soc. 2011, 133 (41), 16422.

(27) Keuleyan, S. E.; Guyot-Sionnest, P.; Delerue, C.; Allan, G. ACS Nano 2014, 8 (8), 8676.

(28) Sagar, L. K.; Walravens, W.; Maes, J.; Geiregat, P.; Hens, Z. J. Phys. Chem. C 2017, 121 (25), 13816.

(29) Izquierdo, E.; Robin, A.; Keuleyan, S.; Lequeux, N.; Lhuillier, E.; Ithurria, S. J. Am. Chem. Soc. 2016, 138 (33), 10496.
(30) Shen, G.; Chen, M.; Guyot-Sionnest, P. J. Phys. Chem. Lett. 2017, 2224.

(31) Rinnerbauer, V.; Hingerl, K.; Kovalenko, M.; Heiss, W. Appl. Phys. Lett. 2006, 89 (19), 193114.

(32) Lhuillier, E.; Keuleyan, S.; Guyot-Sionnest, P. Nanotechnology 2012, 23 (17), 175705.

(33) König, M.; Wiedmann, S.; Brüne, C.; Roth, A.; Buhmann, H.; Molenkamp, L. W.; Qi, X.-L.; Zhang, S.-C. Science 2007, 318 (5851), 766.

(34) Malkova, N.; Bryant, G. W. Phys. Rev. B 2010, 82 (15), 155314.

(35) Rowe, D. J.; Jeong, J. S.; Mkhoyan, K. A.; Kortshagen, U. R. Nano Lett. 2013, 13 (3), 1317.

(36) Gordon, T. R.; Paik, T.; Klein, D. R.; Naik, G. V.; Caglayan, H.; Boltasseva, A.; Murray, C. B. Nano Lett. 2013, 13 (6), 2857.

(37) Buonsanti, R.; Llordes, A.; Aloni, S.; Helms, B. A.; Milliron, D. J. Nano Lett. 2011, 11 (11), 4706.

(38) Delerue, C. Nano Lett. 2017, 17 (12), 7599.

(39) Pearson, R. G. J. Am. Chem. Soc. 1963, 85 (22), 3533.

(40) Chen, M.; Guyot-Sionnest, P. ACS Nano 2017, 11 (4), 4165.

(41) Lhuillier, E.; Ithurria, S.; Descamps-Mandine, A.; Douillard, T.; Castaing, R.; Xu, X. Z.; Taberna, P.-L.; Simon, P.; Aubin, H.; Dubertret, B. J. Phys. Chem. C 2015, 119 (38), 21795.

(42) Robin, A.; Livache, C.; Ithurria, S.; Lacaze, E.; Dubertret, B.; Lhuillier, E. ACS Appl. Mater. Interfaces 2016, 8 (40), 27122.

(43) Martinez, B.; Livache, C.; Notemgnou Mouafo, L. D.; Goubet, N.; Keuleyan, S.; Cruguel, H.; Ithurria, S.; Aubin, H.; Ouerghi, A.; Doudin, B.; Lacaze, E.; Dubertret, B.; Silly, M. G.; Lobo, R. P. S. M.; Dayen, J.-F.; Lhuillier, E. ACS Appl. Mater. Interfaces 2017, 9 (41), 36173. 
Table of Content

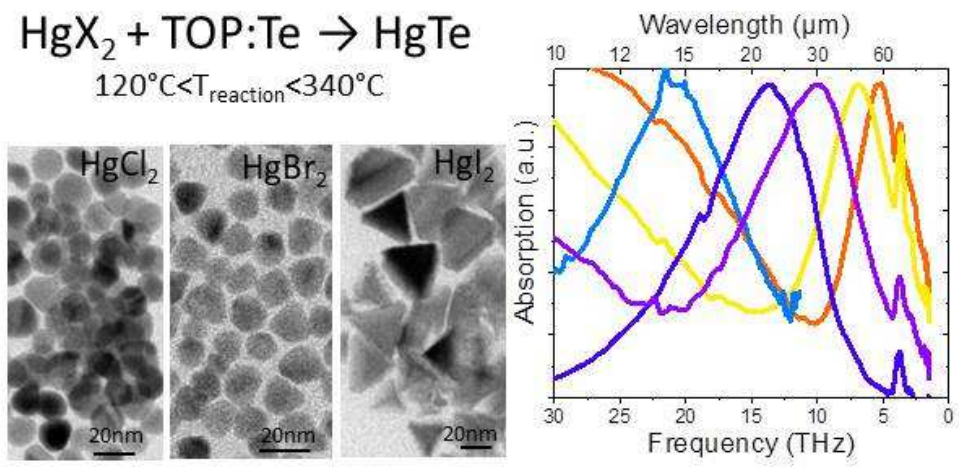

